OPEN ACCESS

Check for updates

\section{Air pollution and family related determinants of asthma onset and persistent wheezing in children: nationwide case-control study}

\author{
Gitte J Holst, ${ }^{1}$ Carsten B Pedersen, ${ }^{2}$ Malene Thygesen, ${ }^{2}$ Jørgen Brandt, ${ }^{3}$ Camilla Geels, ${ }^{3}$ \\ Jakob H Bønløkke, ${ }^{4}$ Torben Sigsgaard ${ }^{1}$
}

${ }^{1}$ Department of Public Health,

Section of Environment,

Occupation and Health, Aarhus University, Bartholin Allé 2, 8000 Aarhus C, Denmark

${ }^{2}$ National Centre for RegisterBased Research, School of Business and Social Sciences,

${ }^{3}$ Department of Environmental Science, Aarhus University, Roskilde, Denmark

${ }^{4}$ Department of Occupational and Environmental Medicine,

Danish Ramazzini Centre,

Aalborg University Hospital,

Aalborg, Denmark

TSigsgaard ts@ph.au.dk

(or @torbensigsgaard on Twitter: ORCID 0000-0002-2043-7571)

Additional material is published online only. To view please visit the journal online.

Cite this as: BM/2020;370:m2791 http://dx.doi.org/10.1136/bmj.m2791

Accepted: 24 June 2020 Aarhus University, Denmark

Correspondence to:

\section{ABSTRACT}

OBJECTIVE

To identify risk factors (air pollution and family related) for the onset of asthma and persistent wheezing in children.

DESIGN

Nationwide case-control study.

SETTING

Denmark.

\section{PARTICIPANTS}

All Danish children born from 1997 to 2014 and followed for asthma onset and persistent wheezing from age 1 year to 15 years.

MAIN OUTCOME MEASURE

Onset of asthma and persistent wheezing.

\section{RESULTS}

A higher incidence of asthma was found in children of parents with asthma (adjusted hazard ratio 2.29

(95\% confidence interval 2.22 to 2.35 ) and mothers who smoked during pregnancy $(1.20,1.18$ to 1.22$)$, whereas a lower incidence was found in children of parents with high educational attainment $(0.72$, 0.69 to 0.75$)$ and high incomes $(0.85,0.81$ to 0.89$)$. Exposure to particulate matter $\leq 2.5 \mu \mathrm{m}\left(\mathrm{PM}_{2.5}\right)$ and $\leq 10 \mu \mathrm{m}\left(\mathrm{PM}_{10}\right)$ and nitrogen dioxide was associated with an increased risk of asthma and persistent wheezing, with hazard ratios per $5 \mu \mathrm{g} / \mathrm{m}^{3}$ increase in pollutant concentrations 1.05 (1.03 to 1.07) for $\mathrm{PM}_{2.5}$,

\section{WHAT IS ALREADY KNOWN ON THIS TOPIC}

The rapid increase in prevalence of asthma worldwide suggests that along with heredity (familial asthma history), environmental, behavioural, and social factors might also contribute to asthma incidence

Among risk factors, short term peak exposure to air pollution has been associated with exacerbation of asthma, whereas the risks of long term exposure and the timing of exposure for the onset of asthma is less clear

In addition, the role of air pollution and its occurrence with other risk factors, such as socioeconomic status, on asthma is unclear

\section{WHAT THIS STUDY ADDS}

This nationwide study found evidence that heredity, socioeconomic status, and maternal smoking during pregnancy are potential risk factors for new asthma onset and persistent wheezing in children

These findings contribute to the emerging evidence that ambient fine particles smaller than $2.5 \mu \mathrm{m}\left(\mathrm{PM}_{2.5}\right)$ contribute to the development of asthma and persistent wheezing

The results suggest that further reductions in $\mathrm{PM}_{2.5}$ might help to reduce the number of children who develop asthma and persistent wheezing in highly exposed populations
1.04 (1.02 to 1.06) for $\mathrm{PM}_{10}$, and 1.04 (1.03 to 1.04) for nitrogen dioxide. Only the positive association of $\mathrm{PM}_{2.5}$ with asthma and persistent wheezing remained robust across the different models and in sensitivity analyses.

\section{CONCLUSIONS}

The findings of this study suggest that children exposed to higher levels of $\mathrm{PM}_{2.5}$ are more likely to develop asthma and persistent wheezing than children who are not exposed. Other risk factors associated with these outcomes were parental asthma, parental education, and maternal smoking during pregnancy.

\section{Introduction}

Asthma is among the most prevalent diseases in children worldwide. ${ }^{1}$ As children of parents with asthma are more prone to develop the disease, genetic susceptibility has been considered an important risk factor. ${ }^{2}$ The rapid increase in prevalence of asthma and allergy globally suggests that besides genetic factors, environmental and social factors might also play a part.

Exposure to passive smoking is recognised as an important environmental risk factor for the development of asthma in children. ${ }^{34}$ Urbanisation has been associated with asthma, ${ }^{5}$ but it is unknown what factors, or combination of factors, such as environmental exposures, activities, or health behaviours might be part of the association. ${ }^{56}$ Residential area might also reflect socioeconomic status, as measured by parental income, and educational level has been linked with asthma in children. ${ }^{78}$

Peaks in exposure to air pollution have been associated with exacerbation of asthma, ${ }^{9}{ }^{10}$ whereas the role of long term exposure and timing of exposure for asthma onset is less clear. Many studies have been limited to non-representative populations, covering children in families from certain areas and socioeconomic groups. This might introduce selection bias and affect the analysis of the influence of socioeconomic status on asthma and the role of socioeconomic status and related factors in the effect of air pollution.

The development of asthma and wheezing is likely to result from a complex interplay between environmental and social factors, rather than from individual factors alone, underscoring the need to explore the relation between air pollution and asthma in large, representative populations. Using a registry based nationwide approach covering all Danish 
children born during 1997-2014, we explored a combination of air pollution and family related factors potentially contributing to asthma onset and persistent wheezing. We determined whether asthma onset and persistent wheezing was associated with family related factors, whether high levels of air pollution in the children's residential area was associated with an increased risk of asthma and persistent wheezing, and whether associations of air pollution with asthma and persistent wheezing vary by family related factors.

\section{Methods}

\section{Study design and study population}

We used survival analysis methods to follow Danish children born from 1997 to 2014 for asthma onset and persistent wheezing using a national registry based, matched case-control design. Cases were drawn from the entire Danish population and comprised all children with a diagnosis of asthma or with a minimum of two prescriptions for asthma medicine $(n=122842)$ from their 1st to 15 th birthday. For each case we selected 25 controls at random who could serve as controls several times ( $\mathrm{n}=3069943)$, had no asthma diagnosis, and were matched by sex and birthday to within one week. All children and their parents were born in Denmark.

\section{Asthma and wheezing outcome assessment}

We identified children with asthma and persistent wheezing from the Danish National Patient Register, which contains data on all people admitted to public hospitals from 1977 onwards, and we obtained information on dispensed drugs from the Danish National Prescription Registry from 1994 and onwards. Cases were classified as having asthma or persistent wheezing, or both if they had been admitted to a public hospital or been treated as an outpatient and received a first diagnosis of asthma (international classification of diseases, 10th revision; ICD-10 code J45 or J46) as the final diagnosis at the visit (release diagnosis), or they had a minimum of two prescriptions for asthma medicine (based on the Anatomical Therapeutic Chemical Classification System; adrenergic inhalants (R03A), other drugs for obstructive airway diseases (R03B), adrenergics for systemic use (R03C), and other systemic drugs for obstructive airway disease (R03D)). A recent Danish validation study compared data on asthma discharge diagnosis from the national register with prescription data and found that true asthma in children could be identified with reasonable accuracy; the positive predictive value of having two different asthma drugs prescribed in one year was $80 \%$ for the presence of true asthma, with a sensitivity of $59 \% .{ }^{11}$ Moreover, validation studies concluded that by using this definition of asthma both true cases and virus related wheezing as well as persistent wheezing due to other environmental factors would likely be identified. ${ }^{11-13}$ Therefore in this study we use both the terms asthma and persistent wheezing for the outcome. We defined the date of onset as either the day when asthma was first diagnosed or the date of a second prescription for asthma drugs, whichever came first.

\section{Exposure to air pollution}

Concentrations of pollutants were modelled on an hourly basis for all of Denmark from 1 January 1997 to 31 December 2014. Pollutants of interest comprised several different gases and aerosols or particles: ozone, nitrogen dioxide $\left(\mathrm{NO}_{2}\right)$, nitrate $\left(\mathrm{NO}_{3}^{-}\right)$, combined nitrogen oxide (NO) and nitrogen dioxide, particulate matter $\leq 2.5 \mu \mathrm{m}\left(\mathrm{PM}_{2.5}\right)$ and $\leq 10 \mu \mathrm{m}\left(\mathrm{PM}_{10}\right)$, sulphur dioxide $\left(\mathrm{SO}_{2}\right)$, sulfate $\left(\mathrm{SO}_{4}^{-}\right)$, ammonia $\left(\mathrm{NH}_{3}\right)$, ammonium $\left(\mathrm{NH}_{4}^{+}\right)$, secondary inorganic aerosols (the sum of nitrate, sulfate, and ammonium), elemental carbon, organic carbon, and sea salt. Modelled air pollution data were obtained from the newly updated Danish air pollution modelling system DEHM/ UBM(THOR) ${ }^{14-16}$ (see supplementary file for further details). We used an average of hourly air pollution concentrations during the past 3, 6, and 12 months before the index date for which the case and matched controls were identified. Air pollution concentrations were linked to the children's residential addresses with a detailed spatial resolution of $1 \mathrm{~km} \times 1 \mathrm{~km}$ grid cells, taking into account any changes in residence.

\section{Assessment of family related factors}

We obtained information about parental asthma from the Danish National Patient Register based on information on asthma diagnosis (ICD-8, 493; ICD10 , J45 or J46) and a minimum of two prescriptions of asthma medicine. From the Medical Birth Registry, for a subgroup of the study population $(n=120521)$, we had information on mothers' reported smoking at the first meeting with a midwife during pregnancy. Smoking information was categorised into two variables. One variable categorised mothers as either non-smoker, quit smoking during pregnancy, and smoking during pregnancy. A second, more detailed variable also included daily number of cigarettes smoked. Information on parental education was derived from the education register and reflected the highest completed parental education for the mother or the father and was categorised into primary school and short, medium, and long education. Information on parental income was obtained from the income register and categorised into mother's and father's income based on the quintiles of income for the general population. To study both parental education and income, a combined variable was generated adding the level of income (level 1-5) or education (level 1-4) for each parent generating a seven level categorical variable for parental education and a nine level variable for parental income.

\section{Statistical analysis}

We used survival analyses techniques to follow all children from their 1st to their 15th birthday between 1998 and 2014 for the risk of asthma. Risk ratios equivalent to hazard ratios along with $95 \%$ confidence intervals were estimated using conditional logistic 
regression with each case-control set forming separate stratums to investigate the association of air pollution and family related factors of asthma onset and persistent wheezing.

Family related factors were analysed as categorical variables and air pollutant concentrations were analysed for each 1,5 , and $10 \mu \mathrm{g} / \mathrm{m}^{3}$ increase in concentrations using exposure to air pollution during the past 12 months before asthma onset as the primary exposure of interest.

To study the association of air pollution with risk of asthma and persistent wheezing, we undertook three a priori specified confounder models. Model 1 included matching the variables of age, sex, date of birth, and calendar year. Model 2 additionally adjusted for parental asthma, and model 3 additionally adjusted for parental education and parental income.

We conducted several sensitivity analyses based on confounder model 3 . We explored the past 3, 6, and 12 month exposure time windows, different exposure concentrations comparing each interquartile range with each $\mu \mathrm{g}$ increase in concentration, adjustment for other air pollutants one at a time, adjustment for maternal smoking during pregnancy, trends in risk over time, and first born children.

To study the consistency among effects of air pollution, we stratified model 3 by sex (boy versus girl), age groups ( $<6$ years and $\geq 6$ years), parental asthma (none, only father asthmatic, only mother asthmatic, both parents asthmatic), maternal smoking during pregnancy (nonsmoker, quit smoking during pregnancy, smoking during pregnancy), parental educational level (level 1-7), and income level (level 1-9).

Statistical analyses were conducted using STATA (version 14. StataCorp, College Station, TX).

\section{Patient and public involvement}

As this is a register based study, patients and public were not involved in the design, conduct, or reporting of this research. The study did not include the funding or researchers and patient training necessary to include patients or members of the public in the design of the study.

\section{Results}

In total, 3192785 children were included in the study. Of these, 122842 children were identified as having asthma and persistent wheezing. Most cases $(83 \%$, $\mathrm{n}=101348$ ) occurred among children younger than 3 years (supplementary table E1), with a mean age of 1.9 years (SD 2.2) for developing asthma and persistent wheezing.

Asthma onset and persistent wheezing in relation to family related factors

Parental asthma was positively associated with a higher risk of asthma and persistent wheezing in offspring (supplementary table E1). If mothers had asthma this was associated with a higher risk than if fathers had asthma (hazard ratio 1.72 (95\% confidence interval 1.72 to 1.77 ) versus 1.51 (1.48 to
1.53)). Having two parents with asthma was associated with a 2.40-fold (2.34-fold to 2.47-fold) increased risk of asthma and persistent wheezing. Maternal smoking during pregnancy was associated with an increased risk of asthma, and a positive dose-response relation was found between the number of cigarettes smoked daily and an increased risk of asthma and persistent wheezing. Moreover, both mother's and father's incomes as well as educational levels were independently associated with asthma and persistent wheezing, showing that higher household income and educational level were associated with a reduced risk of asthma and persistent wheezing. This finding was most pronounced for maternal education level, with a reduced risk of asthma and persistent wheezing (hazard ratio $0.58,95 \%$ confidence interval 0.56 to 0.59 ) in children of mothers with the highest compared with the lowest education levels. The combined variables of parental income and education showed a similar trend in associations. When the determinants were mutually adjusted for one another, the association of parental income with asthma and persistent wheezing was only shown for the four highest income levels compared with the lowest income level (fig 1, see supplementary table E2). To study trends in asthma risk over time, five year intervals were compared: 1998-2002, 2003-08, and 2009-14. The results remained robust for parental asthma, parental education, and maternal smoking during pregnancy, but were not similarly consistent over time for parental income (supplementary table E3).

Risk of asthma and persistent wheezing from high levels of air pollution in children's residential area Mean air pollutant concentrations ranged considerably, from $0.4 \mu \mathrm{g} / \mathrm{m}^{3}$ (SD 0.1) for elemental carbon to $58.8 \mu \mathrm{g} / \mathrm{m}^{3}$ (SD 5.1) for ozone (table 1). Air pollutant concentrations were generally moderately to highly correlated (supplementary table E4), with the highest correlations found between secondary inorganic aerosols, ammonium, sulfate, and nitrate (Pearson's correlation coefficient $r=0.71-0.95)$, elemental carbon and organic carbon $(r=0.98)$, nitrogen dioxide and combined nitrogen oxide and nitrogen dioxide $(\mathrm{r}=0.98), \mathrm{PM}_{2.5}$ and $\mathrm{PM}_{10}(\mathrm{r}=0.95)$, and between ammonium and $\mathrm{PM}_{2.5}(\mathrm{r}=0.88)$ and ammonium and $\mathrm{PM}_{10}(\mathrm{r}=0.83)$.

In the first analyses (model 1) (fig 2, supplementary table E5), $\mathrm{PM}_{2.5}, \mathrm{PM}_{10}$, nitrate, ammonium, and secondary inorganic aerosols were positively associated with asthma and persistent wheezing, whereas nitrogen dioxide, sulphur dioxide, elemental carbon, and organic carbon were inversely associated with asthma and persistent wheezing. When these effects were adjusted for parental asthma (model 2, fig 2), findings were similar, although the point estimates were slightly attenuated. After adjustment for parent's education and income (model 3, fig 2), the positive association for secondary inorganic aerosols and ammonium disappeared, but the positive associations between $\mathrm{PM}_{2.5}, \mathrm{PM}_{10}$, nitrogen dioxide and asthma remained, with hazard ratios for asthma and 


\section{Parental asthma}

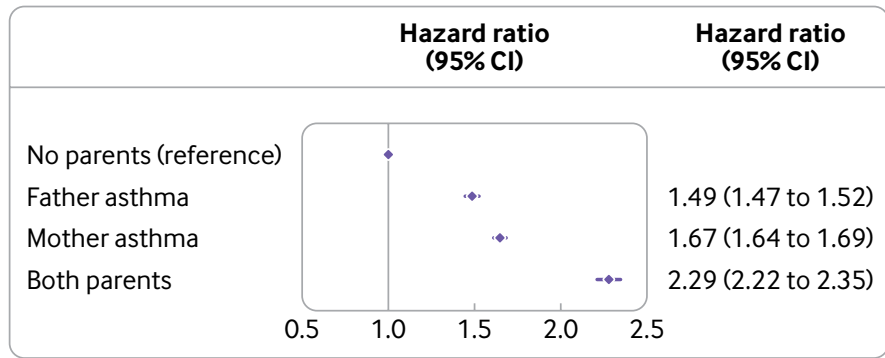

\section{Parental income}

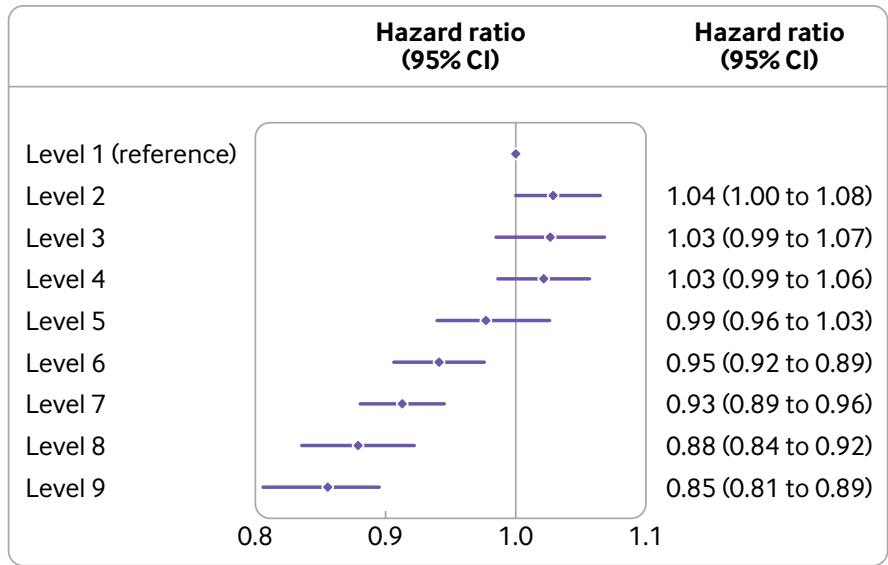

\section{Maternal smoking during pregnancy}

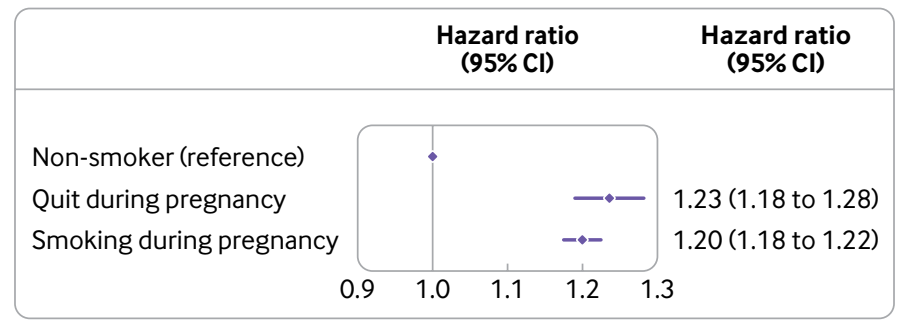

\section{Parental education}

\begin{tabular}{|c|c|c|}
\hline & $\begin{array}{l}\text { Hazard ratio } \\
(95 \% \mathrm{Cl})\end{array}$ & \multirow[t]{2}{*}{$\begin{array}{c}\text { Hazard ratio } \\
(95 \% \mathrm{Cl})\end{array}$} \\
\hline Level 1 (reference) & - & \\
\hline Level 2 & $-\bullet-$ & $0.98(0.95$ to 1.00$)$ \\
\hline Level 3 & $-\bullet$ & 0.93 (0.90 to 0.95) \\
\hline Level 4 & $-\bullet$ & $0.88(0.86$ to 0.91$)$ \\
\hline Level 5 & $-\bullet-$ & 0.82 (0.80 to 0.85$)$ \\
\hline Level 6 & -•- & $0.76(0.73$ to 0.79$)$ \\
\hline Level 7 & $-\bullet$ & 0.72 (0.69 to 0.75$)$ \\
\hline 0.6 & 0.9 & \\
\hline
\end{tabular}

Fig 1 | Effects of family related factors on risk of asthma and persistent wheezing after adjustment for age, calendar year, parental asthma, parental education, parental income, and mother's smoking behaviour during pregnancy. Level 1 refers to the lowest level of parental education and parental income

persistent wheezing per $5 \mu \mathrm{g} / \mathrm{m}^{3}$ increase in pollutant concentrations of 1.05 (1.03 to 1.07) for $\mathrm{PM}_{2.5}, 1.04$ (1.02 to 1.06) for $\mathrm{PM}_{10}$, and 1.04 (1.03 to 1.04 ) for nitrogen dioxide. Positive associations were also found for sulphur dioxide, nitrogen dioxide, and combined nitrogen oxide and nitrogen dioxide, whereas ozone and sea salt were inversely associated with asthma and persistent wheezing.

Robustness of the results in model 3 were investigated, considering: exposure time windows of 3, 6, and 12 months (supplementary table E6); differences in results for increases in interquartile ranges versus increases for each 1,5 , and $10 \mu \mathrm{g} / \mathrm{m}^{3}$ increment in concentrations (supplementary table E7); adjusting for any other pollutant by including one pollutant simultaneously in each logistic regression analysis in a two pollutant model (supplementary table E8); adjusting for maternal smoking during pregnancy (supplementary table E9); investigating trends in risk for asthma and persistent wheezing in relation to air pollution over time (supplementary table E10); and studying firstborn children to explore whether associations were related to shared factors in certain families (supplementary table E11). These sensitivity analyses showed that associations of $\mathrm{PM}_{2.5}$ with asthma and persistent wheezing remained robust for direction, magnitude, and statistical significance, whereas the findings for the other air pollutants were not consistently robust.

\section{Effect of air pollution across subpopulations}

Stratified analyses of air pollution with asthma and persistent wheezing by sex, age group, parental asthma, maternal smoking during pregnancy, and parental educational and income level showed consistency between boys and girls (supplementary table E12), parental asthma (supplementary table E13), parental educational level (supplementary table E14), income level (supplementary table E15), and maternal smoking status during pregnancy (supplementary table E16). When considering different age groups ( $<6$ years and $\geq 6$ years) (fig 3 , supplementary table E17), associations between air pollutants and asthma and persistent wheezing showed a different pattern, and strength of associations for children younger than 6 years and 6 years or older. For children aged 6 years or older, no associations were found between $\mathrm{PM}_{2.5}, \mathrm{PM}_{10}$, and nitrate and asthma and persistent wheezing, whereas inverse associations were found for ammonium, sea salt, and ozone, and positive associations were found for elemental carbon and organic carbon.

\section{Discussion}

In this nationwide study, we found that Danish children who had parents with asthma, a mother who smoked during pregnancy, or parents with low education and low income were at a higher risk of developing asthma and persistent wheezing independently of exposure 


\begin{tabular}{|c|c|c|c|c|c|c|}
\hline \multirow[b]{2}{*}{ Pollutants } & \multirow[b]{2}{*}{ Mean (SD) } & \multicolumn{5}{|c|}{ Centile } \\
\hline & & 5th & 25th & 50th & 75th & 95th \\
\hline \multicolumn{7}{|l|}{ Air pollutants $\left(\mu \mathrm{g} / \mathrm{m}^{3}\right)$} \\
\hline \multicolumn{7}{|l|}{ Gases: } \\
\hline Ozone & $58.8(5.1)$ & 50.2 & 55.2 & 59.0 & 62.5 & 66.8 \\
\hline Nitrogen dioxide & $14.9(5.1)$ & 7.7 & 10.9 & 14.2 & 18.7 & 23.9 \\
\hline Nitrogen oxide+nitrogen dioxide & $18.2(7.5)$ & 8.4 & 12.2 & 16.6 & 23.2 & 31.9 \\
\hline Sulphur dioxide & $4.22(1.9)$ & 1.7 & 2.7 & 3.8 & 5.2 & 8.0 \\
\hline \multicolumn{7}{|l|}{ Particles } \\
\hline \multicolumn{7}{|l|}{ Total: } \\
\hline $\mathrm{PM}_{25}$ & $12.2(1.5)$ & 9.7 & 10.9 & 12.1 & 13.3 & 14.8 \\
\hline $\mathrm{PM}_{10}$ & $14.7(1.6)$ & 12.2 & 13.5 & 14.7 & 15.8 & 17.5 \\
\hline \multicolumn{7}{|l|}{ Primary emitted: } \\
\hline Elemental carbon & $0.4(0.1)$ & 0.2 & 0.3 & 0.4 & 0.5 & 0.6 \\
\hline Organic carbon & $0.8(0.2)$ & 0.4 & 0.5 & 0.6 & 0.8 & 1.2 \\
\hline Sea salt & $3.8(0.8)$ & 2.6 & 3.1 & 3.6 & 4.2 & 5.4 \\
\hline \multicolumn{7}{|l|}{ Secondary inorganic: } \\
\hline Sulfate & $6.8(1.9)$ & 4.1 & 5.0 & 6.8 & 8.3 & 9.9 \\
\hline Nitrate & $10.9(1.7)$ & 8.3 & 9.4 & 10.7 & 12.0 & 14.0 \\
\hline
\end{tabular}

to air pollution. Sensitivity analyses showed robust associations between parental asthma, parental education, and maternal smoking during pregnancy and asthma and persistent wheezing in offspring. For associations of air pollution concentrations with asthma and persistent wheezing, the most consistent finding was the positive association of $\mathrm{PM}_{2.5}$ with asthma indicating that exposure to $\mathrm{PM}_{2.5}$ might be responsible for an increase in the numbers of children with asthma and persistent wheezing worldwide. Our analyses of effect modification indicated potential susceptibility by age as we found different associations between air pollutant concentrations and asthma in different age groups.

\section{Comparison with previous studies \\ Family related determinants}

The strongest determinant for asthma incidence and persistent wheezing was parental asthma. This was expected, as genetic disposition is recognised as a strong risk factor for the development of asthma and allergy. ${ }^{217}$ Using parental asthma as a proxy for children's genetic disposition for asthma is, however, a proxy of the genetic liability of developing asthma.

We found that maternal smoking during pregnancy was associated with an increased risk of asthma and persistent wheezing in offspring. Exposure to tobacco is well established as an important risk factor for asthma. ${ }^{18}$ Children whose mothers quit smoking during pregnancy had an increased risk of childhood asthma and persistent wheezing, indicating that even some exposure to tobacco smoke during gestation is harmful, and this is supported by other studies. ${ }^{8}$ However, we had no information on exposures of the children to smoking after delivery, and therefore it is unclear whether it is exposure during pregnancy or after delivery that influences the results.

Among other risk factors for asthma and persistent wheezing, we found parental income and educational level to be significant. Generally, heterogeneous results have been found between socioeconomic status and asthma in previous studies, ${ }^{7} 1920$ possibly as a result of difficulties in assessment of socioeconomic status and the uncertainty about whether socioeconomic status is the driver for development of asthma. Health behaviour related to socioeconomic status-physical activity, diet, alcohol consumption, smoking, and healthcare-are suggested to be among the underlying drivers for the development of asthma. ${ }^{21}$ Information on the children's or their family's lifestyle could have provided further insights. This information was not, however, available from the registries.

\section{Air pollution and potential effect modifiers}

Despite heterogeneity in study designs and methods used across studies, in our study the results were in line with a meta-analysis ${ }^{22}$ and a population based birth cohort study, ${ }^{23}$ together with other prospective studies that have identified $\mathrm{PM}_{2.5}$ as a potential risk factor for asthma in children. ${ }^{24-26}$ Notably, two of the mentioned studies even observed an increased risk of asthma at $\mathrm{PM}_{2.5}$ levels lower than the ones reported in our study (overall mean $12.2 \mu \mathrm{g} / \mathrm{m}^{3}$ (SD 1.5) in our study). The pollution levels in Denmark are lower than in, for example, highly populated regions in central Europe, but are higher than, for example, the rest of Scandinavia. The proposed annual limit in Europe for $\mathrm{PM}_{2.5}$ is $20 \mu \mathrm{g} / \mathrm{m}^{3}$; however, further reductions in $\mathrm{PM}_{2.5}$ might reduce the number of children developing asthma and having persistent wheezing.

Traffic related air pollution has been suggested to influence the development of asthma, and besides exposure to $\mathrm{PM}_{2.5}$, the effects on asthma in children have been observed for exposure to nitrogen dioxide, ${ }^{27} 28$ even at current low European levels. ${ }^{29}$ This is in accordance with our findings, which showed a general pattern of positive associations for elemental carbon, organic carbon, $\mathrm{PM}_{2.5}, \mathrm{PM}_{10}$, sulphur dioxide, 


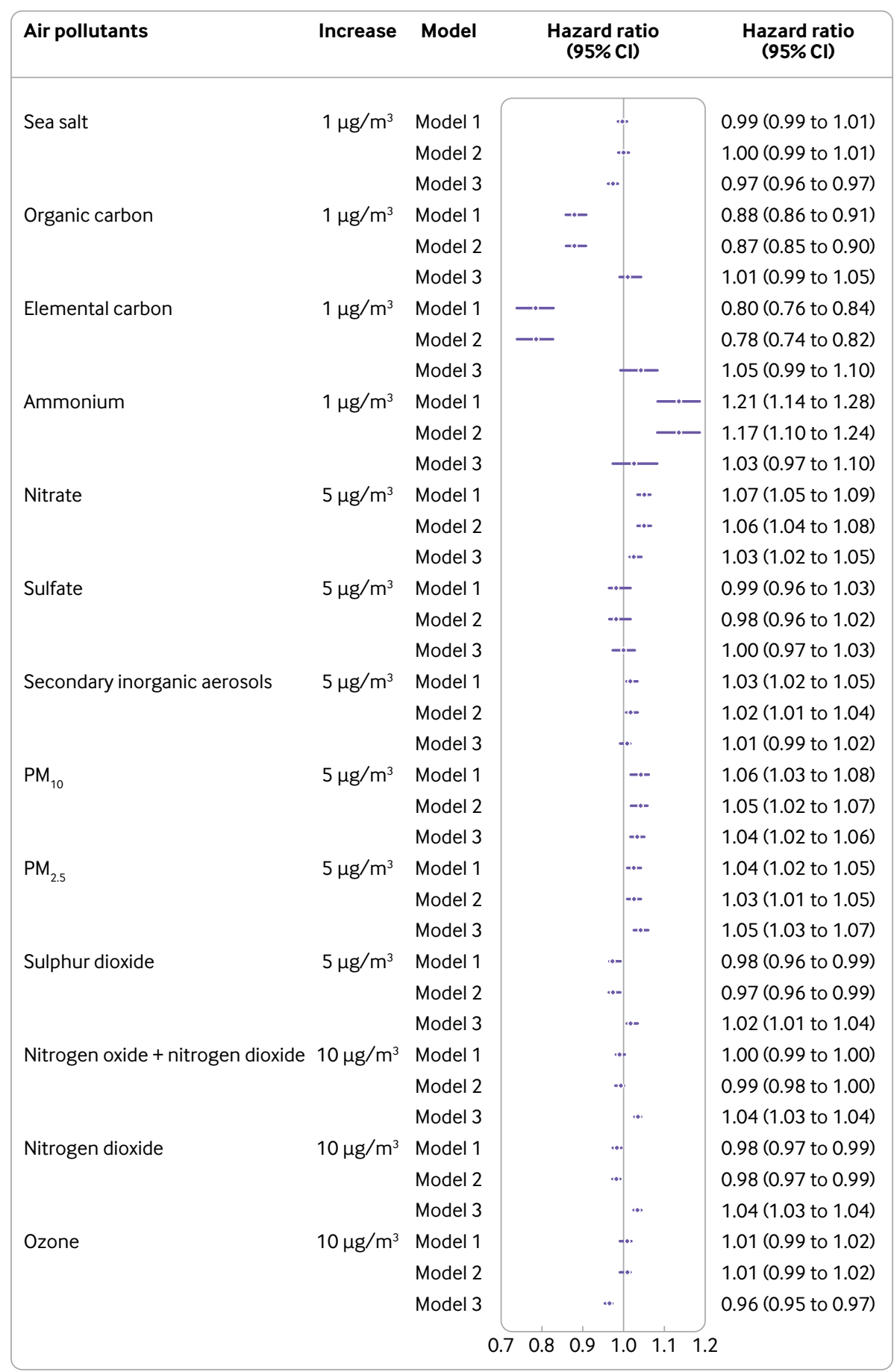

Fig 2 | Effects of air pollutants on risk of asthma and persistent wheezing. Model 1 was adjusted for sex, age, and calendar year. Model 2 was additionally adjusted for parental asthma. Model 3 was additionally adjusted for parental income and parental education. A log 10 scale is used

combined nitrogen oxide and nitrogen dioxide, and nitrogen dioxide with asthma and persistent wheezing. This indicates that for asthma onset, local sources of air pollution (eg, traffic) might be more of a factor than long distance sources. In line with this, the observed inverse associations of ozone and sea salt with asthma and persistent wheezing could reflect the more rural distribution pattern of these pollutants and that ozone is negatively correlated with concentrations of nitrogen dioxide and combined nitrogen oxide and nitrogen dioxide that are increased in urban areas. More long term studies are needed to explore and confirm the role of primary and secondary air pollution emissions and to explore both short term and long term exposure to identify the critical exposure window. Furthermore, the mechanisms underlying the association between air pollution and asthma have not been fully clarified. The present experimental studies have, however, 


\begin{tabular}{|c|c|c|c|c|c|}
\hline \multirow{2}{*}{$\begin{array}{l}\text { Air pollutants } \\
\text { Sea salt }\end{array}$} & \multirow{2}{*}{$\begin{array}{l}\text { Increase } \\
1 \mu \mathrm{g} / \mathrm{m}^{3}\end{array}$} & \multirow{2}{*}{$\begin{array}{l}\text { Model } \\
\text { <6 years }\end{array}$} & \multicolumn{2}{|c|}{$\begin{array}{c}\text { Hazard ratio } \\
(95 \% \mathrm{Cl})\end{array}$} & \multirow{2}{*}{$\begin{array}{c}\begin{array}{c}\text { Hazard ratio } \\
(95 \% \mathrm{Cl})\end{array} \\
0.97(0.97 \text { to } 0.98\end{array}$} \\
\hline & & & & & \\
\hline & & $\geq 6$ years & $\cdots$ & & 0.92 (0.89 to 0.95$)$ \\
\hline \multirow[t]{2}{*}{ Organic carbon } & $1 \mu \mathrm{g} / \mathrm{m}^{3}$ & $<6$ years & & & 1.00 (0.97 to 1.02$)$ \\
\hline & & $\geq 6$ years & & $-\cdot-$ & 1.43 (1.29 to 1.59$)$ \\
\hline \multirow[t]{2}{*}{ Elemental carbon } & $1 \mu \mathrm{g} / \mathrm{m}^{3}$ & $<6$ years & & & 1.02 (0.97 to 1.08$)$ \\
\hline & & $\geq 6$ years & & & 2.03 (1.63 to 2.51$)$ \\
\hline \multirow[t]{2}{*}{ Ammonium } & $1 \mu \mathrm{g} / \mathrm{m}^{3}$ & $<6$ years & & & $1.05(0.98$ to 1.11$)$ \\
\hline & & $\geq 6$ years & - & & 0.72 (0.54 to 0.94$)$ \\
\hline \multirow[t]{2}{*}{ Nitrate } & $5 \mu \mathrm{g} / \mathrm{m}^{3}$ & $<6$ years & & & $1.03(1.02$ to 1.05$)$ \\
\hline & & $\geq 6$ years & & & 0.97 (0.87 to 1.07$)$ \\
\hline \multirow[t]{2}{*}{ Sulfate } & $5 \mu \mathrm{g} / \mathrm{m}^{3}$ & $<6$ years & & & 1.01 (0.97 to 1.03$)$ \\
\hline & & $\geq 6$ years & & & 0.93 (0.81 to 1.08$)$ \\
\hline \multirow[t]{2}{*}{ Secondary inorganic aerosols } & $5 \mu \mathrm{g} / \mathrm{m}^{3}$ & $<6$ years & & & 1.01 (0.99 to 1.02$)$ \\
\hline & & $\geq 6$ years & & & $0.98(0.92$ to 1.05$)$ \\
\hline \multirow[t]{2}{*}{$\mathrm{PM}_{10}$} & $5 \mu g / m^{3}$ & $<6$ years & & & $1.05(1.02$ to 1.07$)$ \\
\hline & & $\geq 6$ years & $-\cdot$ & & $0.93(0.86$ to 1.00$)$ \\
\hline \multirow[t]{2}{*}{$\mathrm{PM}_{2.5}$} & $5 \mu \mathrm{g} / \mathrm{m}^{3}$ & $<6$ years & & & 1.05 (1.03 to 1.07$)$ \\
\hline & & $\geq 6$ years & & & $1.08(0.99$ to 1.16$)$ \\
\hline \multirow[t]{2}{*}{ Sulphur dioxide } & $5 \mu \mathrm{g} / \mathrm{m}^{3}$ & $<6$ years & & & $1.01(1.00$ to 1.04$)$ \\
\hline & & $\geq 6$ years & & - & $1.11(1.05$ to 1.18$)$ \\
\hline \multirow[t]{2}{*}{ Nitrogen oxide + nitrogen dioxide } & $10 \mu g / m^{3}$ & $<6$ years & & & $1.03(1.03$ to 1.04$)$ \\
\hline & & $\geq 6$ years & & .* & $1.11(1.07$ to 1.15$)$ \\
\hline \multirow[t]{2}{*}{ Nitrogen dioxide } & $10 \mu \mathrm{g} / \mathrm{m}^{3}$ & $<6$ years & & & $1.03(1.02$ to 1.04$)$ \\
\hline & & $\geq 6$ years & & ..- & $1.16(1.11$ to 1.22$)$ \\
\hline \multirow[t]{2}{*}{ Ozone } & $10 \mu g / m^{3}$ & $<6$ years & $\cdot$ & & 0.96 (0.96 to 0.97$)$ \\
\hline & & $\geq 6$ years & $-\cdot-$ & & 0.89 (0.85 to 0.93$)$ \\
\hline
\end{tabular}

Fig 3 | Effects of air pollutants on risk of asthma and persistent wheezing by age groups after adjustment for sex, age, calendar year, parental asthma, parental income, and parental education. A log10 scale is used

proposed that oxidative stress and tissue damage, airway modelling, inflammatory pathways, and immunological responses might play a key role in combination with genetic susceptibility. ${ }^{9}$

Different patterns of associations between air pollutants and asthma and persistent wheezing were found for children younger and older than 6 years. Again, associations were more pronounced for local sources of air pollution. Whether these associations reflect different effects of air pollution in themselves in different age groups or are related to different asthma phenotypes is unclear. Previous studies have suggested that younger children might be more susceptible to the harmful effects of air pollution than older children. ${ }^{30}$ It has been proposed that early onset asthma is related to inflammation and later onset asthma (from around age 6 years) commonly has an allergic origin. ${ }^{31}$ However, we had no information on atopic status, lung function, inflammatory markers, and disease progress for the children, which could have helped to explain potential differences of these factors. Therefore, in future studies, it would be interesting to distinguish between asthma phenotypes to rule out whether they might be associated with air pollutants in different ways.

\section{Strengths and limitations of this study}

A major strength of our study was the registry based design, which provides a large study population, highly comprehensive data, and no selection bias as all Danish children were included in the study with no losses to follow-up. Therefore, the study population is representative of Danish children across all social classes and varied lifestyles in a broad age group compared with previous studies, allowing us to examine the timing of exposure in relation to asthma onset. Additionally, the prospective data collection of both exposure and outcome data ensures temporality (the exposure precedes the outcome) and therefore enhances the possibility of causal interferences. The age and time matched design minimises confounding from factors related to age, sex, and calendar year. Another strength of the study is the high spatial and temporal resolution for various air pollutants, which allowed for a detailed exposure assessment over the full period.

In our study population, we defined asthma as either being diagnosed on hospital discharge or when a child had received a minimum of two prescriptions for asthma drugs. This ensured high accuracy as the 
asthma was diagnosed by a physician and treatment was prescribed by the child's general practitioner. Asthma diagnosis based on hospital diagnosis might reflect more severe or more acute cases of asthma, whereas a diagnosis based on prescription of asthma drugs likely reflects less severe cases of asthma and comprises persistent wheezing related to viruses and other environmental factors. By including two prescriptions, we minimised the risk of including children with transient airway symptoms but no asthma diagnosis.

The moderate to high correlations between the air pollutants in this and similar studies hampers the investigation of pollutant specific effects. When we adjusted for other air pollutants in the two component analyses, the results were similar to those in the primary analyses (in model 3). We cannot, however, rule out confounding by other air related factors that were not adjusted for, such as meteorological conditions, pollen, and fungal spores. As this problem on high correlation is well known, it has been suggested to consider air pollutants as a dynamic mixture of pollutants that interact and change over time rather than as individual exposures in isolation from other pollutants. However, no such ideal statistical method exists.

Furthermore, to define the children's personal exposure we used modelled exposure data to assess ambient air pollution at the children's residential addresses. An underlying assumption was that the children spent most of their time in the area of their residential address. Although personal air monitoring can measure fewer air pollutants, personal monitoring could yield a more valid exposure assessment by monitoring the children's exposure during daily activities and exact locations (ie, day care centres and schools). Owing to the design and size of the study, however, this was not possible. As most of the study population comprised preschool aged children, we believe that the children spent most of their time at home or at a local day care centre. Furthermore, we accounted for changes in residential address, increasing the validity of the exposure assessment.

Besides the studied determinants, other risk factors could have played a role as potential confounders in our study. A shortcoming of our study is therefore the lack of individual level information such as on nutrition and physical activity, factors related to the children's indoor environment, and perinatal and childhood factors, such as delivery by caesarean section, ${ }^{31} 32$ breast feeding, ${ }^{33}$ and infections. ${ }^{34}$

\section{Conclusions}

The findings from this study strengthen the evidence that parental asthma, parental education, and maternal smoking during pregnancy are risk factors for asthma onset and persistent wheezing in children. Moreover, we found that children exposed to high levels of $\mathrm{PM}_{2.5}$ were more likely to develop asthma and to have persistent wheezing. These findings therefore support emerging evidence that exposure to air pollution might influence the development of asthma. This finding needs to be substantiated in future studies.

Contributors: GJH, CBP, and TS conceived the study. GJH, CBP, MT, and TS contributed to the study design. MT, CG, and JB prepared and cleaned the data. JB and CG contributed to the exposure assessment. CBP provided scientific input on statistical methods. GJH performed the data analyses and took the lead in drafting the manuscript. All authors contributed to the interpretation of data, provided critical revisions to the manuscript, and approved the final draft. The corresponding author attests that all listed authors meet authorship criteria and that no others meeting the criteria have been omitted. $\mathrm{GJH}, \mathrm{TS}, \mathrm{CBP}$, and JB act as guarantors.

Funding: This study was supported by NordForsk under the Nordic Programme on Health and Welfare (project No 75007): understanding the link between air pollution and distribution of related health impacts and welfare in the Nordic countries (NordicWelfAir), and by BERTHA-the Danish Big Data Centre for Environment and Health funded by the Novo Nordisk Foundation Challenge Programme (grant NNF170C0027864).

Competing interests: All authors have completed the ICMJE uniform disclosure form at www.icmje.org/coi_disclosure.pdf and declare: support from NordForsk and the Danish Big Data Centre fo Environment and Health, funded by the Novo Nordisk Foundation; no financial relationships with any organisations that might have an interest in the submitted work in the previous three years; no other relationships or activities that could appear to have influenced the submitted work.

Ethical approval: Not required.

Data sharing: Data are not available owing to a strict data sharing agreement. Data on individual characteristics were requested through Statistics Denmark from the Danish Civil Registration System and data on asthma from the Danish National Patient Register. Environmental data can be requested on payment from the Department of Environmental Sciences, Aarhus University. The overall link for information on residential coordinates with exposure assessment, personal characteristics, and diagnosis history was performed within Statistics Denmark, which requires all users to have permission to access data and carry out analyses.

The lead author (the manuscript's guarantor) affirms that the manuscript is an honest, accurate, and transparent account of the study being reported; that no important aspects of the study have been omitted; and that any discrepancies from the study as planned (and, if relevant, registered) have been explained

Dissemination to participants and related patient and public communities: We plan to disseminate the results to relevant patient communities, at conferences, and through popular science articles and newspapers.

This is an Open Access article distributed in accordance with the Creative Commons Attribution Non Commercial (CC BY-NC 4.0) license, which permits others to distribute, remix, adapt, build upon this work non-commercially, and license their derivative works on different terms, provided the original work is properly cited and the use is noncommercial. See: http://creativecommons.org/licenses/by-nc/4.0/.

1 Akinbami L, Simon A, Rossen L. Changing Trends in asthma Prevalence Among Children. Pediatrics. 2016; 137: e2 0152354.

2 Ober C, Yao TC. The genetics of asthma and allergic disease: a 21st century perspective. Immunol Rev 2011;242:10-30.

3 Jayes L, Haslam PL, Gratziou CG, et al, Tobacco Control Committee of the European Respiratory Society. SmokeHaz: systematic reviews and meta-analyses of the effects of smoking on respiratory health. Chest 2016;150:164-79.

4 Burke H, Leonardi-Bee J, Hashim A, et al. Prenatal and passive smoke exposure and incidence of asthma and wheeze: systematic review and meta-analysis. Pediatrics 2012:129:735-44.

5 Rodriguez A, Brickley E, Rodrigues L, Normansell RA, Barreto M, Cooper PJ. Urbanisation and asthma in low-income and middleincome countries: a systematic review of the urban-rural differences in asthma prevalence. Thorax 2019:74:1020-30.

6 Keet CA, Matsui EC, McCormack MC, Peng RD. Urban residence, neighborhood poverty, race/ethnicity, and asthma morbidity among children on Medicaid. J Allergy Clin Immunol 2017;140:822-7.

7 Yap PS, Gilbreath S, Garcia C, Jareen N, Goodrich B. The influence of socioeconomic markers on the association between fine particulate matter and hospital admissions for respiratory conditions among children. Am J Public Health 2013;103:695-702. 
8 Grabenhenrich LB, Gough H, Reich A, et al. Early-life determinants of asthma from birth to age 20 years: a German birth cohort study. J Allergy Clin Immunol 2014;133:979-88.

9 Guarnieri M, Balmes JR. Outdoor air pollution and asthma. Lancet 2014;383:1581-92.

10 Strickland MJ, Darrow LA, Klein M, et al. Short-term associations between ambient air pollutants and pediatric asthma emergency department visits. Am J Respir Crit Care Med 2010;182:307-16.

11 Rubak S, Høst A, Christensen LB, Langfrits MS, Thomsen RW. Validity of asthma diagnoses and patterns of anti-asthmatic drug use in a cohort of 2053 Danish children. Health Sci Rep 2018;1:e77.

12 Stensballe LG, Klans $\varnothing$ L, Jensen A, Haerskjold A, Thomsen SF, Simonsen J. The validity of register data to identify children with atopic dermatitis, asthma or allergic rhinoconjunctivitis. Pediatr Allergy Immunol 2017;28:535-42.

13 Hansen S, Strøm M, Maslova E, Mortensen EL, Granström C, Olsen SF A comparison of three methods to measure asthma in epidemiologic studies: results from the Danish National Birth Cohort. PLoS One 2012;7:e36328.

14 Brandt J, Christensen JH, Frohn LM, Palmgren F, Berkowicz R, Zlatev Z. Operational air pollution forecasts from European to local scale. Atmos Environ 2001;35:S91-8

15 Brandt J, Christensen JH, Frohn LM, Berkowicz R. Air pollution forecasting from regional to urban street scale - implementation and validation for two cities in Denmark. Phys Chem Earth, parts A/B/C 2003;28:335-44. https://www.sciencedirect.com/science/ article/pii/S1474706503000548

16 Brandt J, Silver JD, Frohn LM, et al. An integrated model study for Europe and North America using the Danish Eulerian Hemispheric Model with focus on intercontinental transport of air pollution. Atmos Environ 2012;53:156-76.

17 Bjerg A, Hedman L, Perzanowski MS, Platts-Mills T, Lundbäck B, Rönmark E. Family history of asthma and atopy: in-depth analyses of the impact on asthma and wheeze in 7- to 8-year-old children. Pediatrics 2007;120:741-8.

18 Hollams EM, de Klerk NH, Holt PG, Sly PD. Persistent effects of maternal smoking during pregnancy on lung function and asthma in adolescents. Am J Respir Crit Care Med 2014;189:401-7.

19 Winquist A, Klein M, Tolbert P, Flanders WD, Hess J, Sarnat SE. Comparison of emergency department and hospital admissions data for air pollution time-series studies. Environ Health 2012;11:70

20 Shmool JL, Kubzansky LD, Newman OD, Spengler J, Shepard P, Clougherty JE. Social stressors and air pollution across New York City communities: a spatial approach for assessing correlations among multiple exposures. Environ Health 2014;13:91.

21 O'Lenick CR, Winquist A, Mulholland JA, et al. Assessment of neighbourhood-level socioeconomic status as a modifier of air pollution-asthma associations among children in Atlanta. J Epidemiol Community Health 2017;71:129-36.

22 Khreis H, Kelly C, Tate J, Parslow R, Lucas K, Nieuwenhuijsen M. Exposure to traffic-related air pollution and risk of development of childhood asthma: A systematic review and meta-analysis. Environ Int 2017:100:1-31.

23 Gehring U, Wijga AH, Hoek G, et al. Exposure to air pollution and development of asthma and rhinoconjunctivitis throughout childhood and adolescence: a population-based birth cohort study. Lancet Respir Med 2015;3:933-42.

24 Carlsten C, Dybuncio A, Becker A, Chan-Yeung M, Brauer M. Trafficrelated air pollution and incident asthma in a high-risk birth cohort. Occup Environ Med 2011;68:291-5.

25 Gehring U, Beelen R, Eeftens M, et al. Particulate matter composition and respiratory health: the PIAMA Birth Cohort study. Epidemiology 2015;26:300-9.

26 Tétreault LF, Doucet M, Gamache P, et al. Childhood exposure to ambient air pollutants and the onset of asthma: an administrative cohort study in Québec. Environ Health Perspect 2016;124:1276-82.

27 Garcia E, Berhane KT, Islam T, et al. Association of changes in air quality with incident asthma in children in California, 1993-2014. JAMA 2019;321:1906-15.

28 Achakulwisut P, Brauer M, Hystad P, Anenberg SC. Global, national, and urban burdens of paediatric asthma incidence attributable to ambient $\mathrm{NO}_{2}$ pollution: estimates from global datasets. Lancet Planet Health 2019;3:e166-78

29 Gehring U, Wijga AH, Koppelman GH, Vonk JM, Smit HA, Brunekreef B. Air pollution and the development of asthma from birth until young adulthood. Eur Respir / 2020;56:2000147.

30 Brunst KJ, Ryan PH, Brokamp C, et al. Timing and duration of trafficrelated air pollution exposure and the risk for childhood wheeze and asthma. Am J Respir Crit Care Med 2015;192:421-7.

31 Duong-Quy S, Todoric K. Childhood Asthma. In: Mahmoudi M, Craig T, Ledford D, eds. Allergy and Asthma. Springer, 2019.

32 Thavagnanam S, Fleming J, Bromley A, Shields MD, Cardwell CR. A meta-analysis of the association between Caesarean section and childhood asthma. Clin Exp Allergy 2008;38:629-33.

33 Sonnenschein-van der Voort AM, Jaddoe VW, van der Valk RJ, et al. Duration and exclusiveness of breastfeeding and childhood asthmarelated symptoms. Eur Respir / 2012;39:81-9.

34 Papadopoulos NG, Christodoulou I, Rohde G, et al. Viruses and bacteria in acute asthma exacerbations--a GA ${ }^{2}$ LEN-DARE systematic review. Allergy 2011;66:458-68.

Supplementary information: additional tables, E1E17 